\title{
Structuring an MCDA model using SSM: A case study in Energy Efficiency
}

\author{
L.P. Neves ${ }^{a, d}$, L.C. Dias ${ }^{b, d}$, C.H. Antunes ${ }^{c, d}$, A. G. Martins ${ }^{c, d}$ \\ a School of Technology and Management, Polytechnic Institute of Leiria, Ap. 4163, 3411-901 \\ Leiria, Portugal.lneves@estg.ipleiria.pt \\ ${ }^{b}$ Faculty of Economics, University of Coimbra, Av Dias da Silva 165, 3004-512 Coimbra, \\ Portugal.1mcdias@fe.uc.pt \\ ${ }^{c}$ Dept. of Electrical Engineering and Computers, University of Coimbra, 3030 Coimbra, \\ Portugal. \{ch,amartins\}@deec.uc.pt \\ d INESC Coimbra, Rua Antero de Quental 199, 3000-033 Coimbra, Portugal.
}

\begin{abstract}
This work presents the use of a problem structuring method, Soft Systems Methodology (SSM), to structure a Multi-Criteria Decision Analysis (MCDA) model, aimed at appraising energy efficiency initiatives. SSM was useful to help defining clearly the decision problem context and the main actors involved, as well as to unveil the relevant objectives for each stakeholder. Keeney's Value Focused Thinking approach was then used to refine and structure the list of objectives according to the perspective of the main evaluators identified. In addition to describing this particular case study, this paper aims at providing some general guidelines on how SSM may facilitate the emergence of objectives for MCDA models.
\end{abstract}

Key words: Problem structuring methods, multiple criteria analysis, SSM, Value Focused Thinking, energy efficiency

\section{Introduction}

Initiatives to promote Energy Efficiency (EE) have been implemented for years in different countries, with a particular relevance in the US after the oil crisis in the seventies and until the beginning of the restructuring process of the electricity market in the mid-eighties. During this period utilities implemented large-scale Demand-Side Management (DSM) initiatives, i.e., initiatives that are aimed at shaping demand according to the interests of Electric Utilities. Strategic Conservation and Load Management were included in the portfolio of initiatives, mostly based on the ability to recover costs through general rate increases under a regulated monopoly framework, and due to high marginal costs and regulatory pressure. These motivations, however, almost disappeared with the advent of competitive electricity markets, leading to an ever decreasing investment in DSM initiatives. In part, DSM was replaced by "Market Transformation" initiatives implemented by governments, such as the imposition of 
standards and mandatory labelling of EE. Nevertheless, in certain situations, the adoption of regulatory frameworks for the remaining monopoly situations, the transmission and distribution businesses, still impels or stimulates the adoption of DSM initiatives.

The need of financing DSM/EE initiatives with public funds, from general rate increases or taxes, led to the formulation of rules to qualify those initiatives. The most complete and widely known set of rules was defined by the California authorities in 1987 (CEC\&CPUC, 1987). It defined tests for different perspectives, concerning different stakeholders, although not stating how these perspectives should be used to qualify initiatives. Eventually, the single rule used became the "societal test", regarding the DSM initiative as a resource comparable with a supply-side option ("Total Resource Cost"), adding externalities and subtracting tax benefits.

A problem with this type of societal tests is that converting externalities into currency units is subject to much imprecision and arbitrariness. For instance, the ExternE project launched by the European Commission (European Commission, 1999a, 1999b; Davis et al., 2000; Krewitt, 2002) for assessing environmental externalities of energy use had to include a significant amount of simplifying assumptions, such as limiting the geographic area affected by pollutants (e.g., not considering effects beyond the boundaries of the EU) or disregarding important pollutants due to lack of compatibility of the valuation processes. Even so, the resulting figures have significant uncertainty ranges which have severe implications for policy (Krewitt, 2002). Last but not the least, the use of external costs may lead to polemic conclusions such as the one cited in Krewitt (2002) in which "the externalities from a badly sited wind turbine (located close to a population, thus high externalities involved) were similar to those from the nuclear fuel chain". In this case the aggregate numbers were hiding important information, namely the different spatial and temporal characteristics of the impacts (the impacts from the wind turbine are local and stop as soon as the turbine stops).

More recent methodologies for evaluating DSM/EE initiatives were those proposed by a consortium of European agencies and utilities participating in a EU SAVE research program (SRCi, 1996) and the California Energy Efficiency Policy Manual (CPUC, 2001, 2003). The main innovation of these methodologies was the consideration of impacts not quantifiable or impossible to measure in monetary units, therefore unsuitable for a Cost-Benefit analysis, which should be listed and used only to help the analysis of the test results on a qualitative basis. These proposals can be perceived as implicitly suggesting a shift from Cost-Benefit analysis to Multi-Criteria Decision Analysis (MCDA). 
This background context provides one of the motivations of this paper: there is clearly a need to properly structure the evaluation of EE initiatives as an MCDA problem formulation, capable of addressing all types of concerns from multiple stakeholders in EE. There is a need to re-assess the roles played by the different actors and how to consider their points-of-view.

In this work, the goal of the MCDA problem formulation is to structure a hierarchy of fundamental objectives for each potential evaluator of EE initiatives, following Keeney's Value Focused Thinking (VFT) methodology (Keeney, 1992). Previous work suggesting lists of impacts (Hobbs and Meier, 2000; Keeney and McDaniels, 1999; SRCi, 1996) were considered as useful starting points, which ought to be complemented with inputs from stakeholder representatives.

The ill-structured nature of the problem suggested adopting a Problem Structuring Method (PSM) (Rosenhead, 1989; Rosenhead and Mingers, 2001), to be used in workshops gathering researchers from INESC Coimbra (the authors' R\&D institute) and representatives of several stakeholders. Checkland's Soft Systems Methodology (SSM) (Checkland, 1989b, 1989a, 1990; Checkland and Scholes, 2000) had been chosen by the authors of this paper for a preliminary reflection about the deficiencies of the current EE evaluation methodologies and the identification of relevant stakeholders (Neves et al., 2004). Hence it was taken as a natural choice to help structuring, or at least unveiling, a hierarchy of fundamental evaluation objectives for MCDA.

A second motivation for this work was then to know whether SSM could be a helpful facilitation tool to help structuring an MCDA model. Previous work (Belton et al., 1997; Bana e Costa et al., 1999; Montibeller et al., 2008) has shown that mapping-based PSMs can be helpful for this purpose. On the other hand, Daellenbach (1997) proposed the use of MCDA to bring about compromise solutions at one of the stages of SSM, whereas Petkov at al. (2007) presented three multimethodology interventions in which SSM was used along with MCDA and other methodologies. Our challenge was then to provide some guidelines, generalising from our contingent context, on how SSM can be used to help generate a "cloud of objectives" to be subsequently structured as a hierarchy.

This paper describes a study where SSM and VFT were used to elicit and structure, respectively, objectives to be used in MCDA models for evaluating EE initiatives, illustrating how these two methodologies may be used fruitfully. Another contribution of this paper is to offer some guidelines on the use of SSM to elicit the objectives of individuals or groups in general. These guidelines (some of which were added in retrospect) do not constitute a precise recipe, but suggest a number of elicitation questions we deem useful. A final contribution of 
this paper is to present structured hierarchies of objectives relevant for the different types of organizations that promote or evaluate EE initiatives.

After introducing in this section the context and the motivation of this study, we outline in Section 2 how the process was conducted and facilitated. Section 3 presents the stages of this particular SSM study, and in parallel it suggests guidelines on how SSM may be used in any other context to elicit a "cloud of objectives" from relevant stakeholders. The development of trees of fundamental objectives based on this "cloud" is then explained in Section 4, and finally some concluding remarks are drawn in Section 5.

\section{The intervention process}

The process of using SSM to generate a "cloud of objectives" for MCDA and structuring this cloud using Value Focussed Thinking spanned a period of several months. As it is often the case, there is not a straightforward answer to the question of who is the client of this study. Indeed, this was not the typical intervention where a paying client hires external helpers (and/or assigns internal staff) to address a problem situation. We can identify, however, multiple layers of clients of this study.

We can define that a client is a person or an entity that deems something ought to be done to improve a problem situation and allocates resources to try to improve it, or at least to increase his knowledge about it. Furthermore, this person or entity triggers and ends the process, assessing how much its results are requisite with regards to its aims. Then, there are two clients for this study: INESC Coimbra at an institutional level and the first author of this work, at a more personal level. INESC Coimbra is an R\&D institute that includes energy planning and rational use of energy as one of its most important research and consulting areas, which in the past had already assisted a major utility in DSM studies during the 1990s. INESC Coimbra wanted to learn more about innovative EE initiatives and their evaluation, preparing itself for future intervention in this area, and allocated several of its researchers (including the authors of this paper) for this task. The first author of this paper took this study to be the subject of his $\mathrm{PhD}$ dissertation (Neves, 2005), hence he held a particular stake in this study.

At a general level, there are two types of not directly intervening clients of this study, given the fact that its outputs were to be made public. One is society as a whole, as a beneficiary of any improvements in EE. The other one is any potential proponent or evaluator of EE initiatives. Although this study has benefited from the contributions of specialists 
working for such entities, they were not participating as actual decision-makers, but as experts with an insider's view of different perspectives.

The first part of the study consisted in the use of SSM to structure the initial 'messy situation' and to help unveiling a "cloud of objectives" for a multi-criteria evaluation of EE initiatives. This was accomplished with the help of a group of experts, which included representatives from an electrical transmission company, an energy services company, an association of consumers, the Portuguese electrical sector regulator, and the Portuguese Directorate-General for Energy, as well as researchers from INESC Coimbra, including members of its management board. Rather than interviewing each of these experts in separate, we felt it would be more fruitful to gather these experts in workshops, crossing perspectives and fostering creativity. Two workshops were held, with some 'off-line' work in-between. The first author of this paper was the process facilitator in both workshops, and the other authors joined him for off-line discussion and structuring.

The second part of the study was the refinement of the "cloud of objectives" obtained and the development of trees of fundamental objectives based on Keeney's Value Focused Thinking guidelines. This analysis has been performed by the authors of this paper aiming for a final structure of objectives that would be seen as requisite by the direct clients of this study: INESC Coimbra and the first author.

\section{Using SSM to elicit objectives}

\subsection{The "finding out" stage}

An SSM intervention typically consists of a sequence of activities, each one building on the constructs and insights derived from the preceding ones: (1) enter the situation considered problematical; (2) express the problem situation; (3) formulate root definitions (CATWOE) of relevant systems of purposeful activities; (4) build conceptual models of the systems named in the root definitions; (5) compare models with real-word activities; (6) define possible changes that are both desirable and feasible; (7) take action to improve the problem situation. This sequence does not need to be linear: it is possible to return to an earlier activity at any moment. SSM begins with the "finding out" stage (activities 1 and 2), where a description of the problem situation is made. There are different approaches to this first objective, a description of the social and political systems through the so-called Analysis I (to identify the client, the would-be problem solvers and the 'problem owners'), Analysis II (to establish what social roles are significant, what norms of behaviour are expected from role holders, and by what values performance in role is deemed to be good or bad) and Analysis III (to find out 
through what 'commodities' is power manifested, and how these commodities are obtained, preserved and passed on), also referred as the stream of cultural analysis (Checkland, 1989b; Checkland and Scholes, 2000), and the classic search of structure and "hard to change" features.

Our approach followed the stream of cultural analysis (Checkland, 1989b; Checkland and Scholes, 2000) and its main results were compiled into a rich-picture (figure 1). In this step the main actors, their main roles and concerns were identified. From this identification the main decision-makers who could make use of a new "system to evaluate the interest of energy efficiency initiatives" were chosen: the Energy Efficiency Agency, the Regulator for the remaining monopoly markets, the regulated transmission and distribution companies, and the competitive supply companies.

We learned that the finding out stage originated opportunities to ask questions that can potentially suggest objectives for each actor. For instance, examining the rich-picture eased the discussion the objectives of the Agency, namely concerning its interactions with other actors. This facilitated the identification of objectives such as "third party support" (i.e., support from other parties to EE initiatives), which clearly emerged from the interaction with ESCOs and appliance manufacturers, or policy and budget constraints derived from the interaction with Government. Table 1 and table 2 present a preliminary list of objectives that resulted from this study.

There are several elicitation questions that we can suggest for discussion during the "finding out" stage, most of which were used in our study (while others are being added in retrospect). An initial question is simply to ask why the situation is considered as problematical. The answer will typically suggest objectives that are not currently being met satisfactorily. The identification of relevant actors (clients, would-be problem solvers, 'problem owners', or other) should be completed by an initial assessment of what are the interests (objectives) of each one. Looking at the problem situation from a "social role" perspective - Analysis II (Checkland, 1986, 1989a) - allows inquiring about norms of behaviour and what constitutes good performance in these roles. The discussion about norms or other types of social constraints may show that these exist to meet the objectives of some stakeholder, whereas the values used to deem what good performance is directly translate into objectives of the role holder. Finally, discussing how power is obtained, manifested and preserved - Analysis III (Checkland, 1986, 1989a) - may unveil political objectives such as fairness, need of accountability for decisions made, or need of a strong leadership. 


\subsection{The system definition stage}

The definition of one or more relevant systems is part of another usual SSM stage: Formulation of relevant purposeful activity models. In this stage, the objective is the clear definition of a system model to use as a tool for learning. In terms of a systems thinking, decision alternatives in MCDA will often correspond to options (which may be mutually exclusive or not) that can be incorporated or rejected when designing a new system or when considering changes to an existing system. For instance, hiring a candidate for a job vacancy may be seen as a change to a work group or to a company viewed as a system. In many cases, many systems may be considered for the same actions: alternative sites for a new airport may be seen in the context of a transportation system, in the context of ecosystems, in the context of a town-system, etc. This possibility of modelling multiple perspectives is by itself a strong motivation for the use of SSM for structuring MCDA.

In this study, we felt it would be appropriate to model an evaluation system for EE initiatives, rather than a system of initiatives or systems such as the electricity market or Earth's ecosystem. Some of these systems, however, might have been analysed if the group felt it had missed some important objectives. We opted to define a system general enough to fit each one of the four potential evaluators of EE initiatives. The group converged towards the following System Definition:

"System to evaluate the interest of promoting each initiative to foster the efficiency of energy end-uses considering the direct advantages and disadvantages to the promoter, as to other entities involved."

This definition conveys several important aspects. First, it is not the initiative that is being evaluated, but "the interest of promoting" the initiative, which stresses the need to consider the interests of who promotes the initiative. Second, it acknowledges that the promoter will want to consider the impacts of the initiative on other entities. Furthermore, it focuses on the efficiency of end-uses, thereby excluding efficiency in power generation and transmission.

A root definition was based on a "CATWOE" analysis, which resulted in the following components:

Customer - The initiative promoter, the external sponsor if any, the beneficiaries (the consumers who benefit with the initiative, the society as it concerns to environmental and other benefits, the manufacturers and sellers of promoted equipments, etc.) and victims (energy companies which reduce sales, manufacturers of the replaced equipments). 
Actors - The decision-maker (DM), i.e., the promoter of the initiative, or someone who has the responsibility of evaluating it, due to some contract. One of the entities referred to above.

Transformation - Initiative with unknown interest $\rightarrow$ Interest known.

"Weltanschauung" - An initiative is implemented only if its advantages overwhelm its disadvantages to the promoter, including the ones resulting from the reactions of other entities affected.

Owner - The DM, or someone at a degree above in the hierarchy (the Government as the power above the Agency or the Regulator).

Environment - Capability of obtaining relevant data; Estimation of initiative success (potential adherence by end-users); Budget; International agreements and directives.

The root definition and the related CATWOE analysis applied to each of the evaluation perspectives revealed other important objectives listed in table 3. As in the "Finding out" stage, we can suggest a list of questions for debate that can help unveil objectives in a general case, during the formulation of root definitions according to the CATWOE mnemonic:

- Customer: Asking what benefits or harm may result to the beneficiaries or victims of an activity, and why may these be important to them, leads to a previously discussed question: which interests of the problem-owners are at stake?

- Actors: Asking, for each role, what would be the difference between a good actor and a bad one, can unveil objectives.

- Transformation: A relevant question here, although it overlaps the previous one to a great extent, is how to judge the quality or success of the transformation.

- Weltanschauung: This "world view" statement often indicates, directly or indirectly, some objectives or constraints (e.g., including the reactions of other affected entities in the Weltanschauung leads to think of objectives like minimizing interference with other entities or promoting acceptability from other entities).

- Owner: As the owner is the answer to the question "who could stop this activity?", a relevant question to unveil objectives is "why would the owner want to stop this activity?" (or, less drastically “why would the owner want to downgrade or upgrade this activity?").

- Environmental constraints: Constraints lead to objectives. Some constraints refer to non-disputed rules or norms that cannot be broken, leading to the objective of complying with these norms (e.g. to keep tap water safe to drink). Other constraints reveal objectives 
that may be traded off against other objectives (e.g. to deliver postal packages in less than 36 hours, or to stay within a budget).

The development of the conceptual model is another stage in which some ideas occur due to the need of thinking about the different activities. The definition of criteria for effectiveness, efficacy and efficiency that is part of building a conceptual model leads directly to the expression of objectives. Furthermore, it may be possible to look for objectives hidden in the operational activities. Purpose-seeking questions such as "why is this activity important?" may help unveiling these objectives.

The conceptual model resulting from the workshops is shown in figure 2. Some new objectives relevant identified at this stage are related to the monitoring and control activities:

- Maximise success (participation)

- Maximise assessment capability

- Maximise post-evaluation capability

- Minimise risks (e.g., of failing to meet targets)

- Minimise implementation resources

\subsection{The system comparison stage}

One of the most important stages of SSM is the comparison stage, the use of the models built for comparison and debate about the situation under study. In this stage the model in figure 2 was compared with existing proposals (namely Cost Benefit Analysis and the California Energy Efficiency Policy Manual) under the perspective of each possible DM to learn about the particular concerns and objectives. The need to define monitoring and control activities for Efficacy, Effectiveness and Efficiency (Checkland, 1989a, 1990) also led to an important enrichment towards understanding the problem.

The comparison stage raised a number of issues which should be taken into account on a re-design of an evaluation system:

- There is a need for an evaluation in absolute terms, i.e., each initiative must be classified as a function of its absolute value. The ranking of a set of initiatives may have some importance for the definition of a portfolio, but each initiative should be subject to analysis prior to the inclusion in the portfolio.

- Each analysis must consider the different perspectives at stake as a function of the power relations between actors. There are objectives to look for and restrictions to take into account in each perspective. 
- Many consequences or impacts of the initiatives cannot be quantified or measured in currency terms, or these are difficult and unreliable calculations.

- The system could be handled more easily if different scales were allowed, avoiding difficult and questionable conversions.

- Consequences of initiatives which are difficult to measure should be considered in qualitative terms.

- The DM should be able to make his preferences explicit regarding each consequence's importance and other relevant parameters to the decision process. The current procedures prevent this transparency, hiding tradeoffs inside the conversion formulas or by disregarding all consequences that cannot be reliably expressed in this way.

- There is a need to document thoroughly the decision process in order to support (or put pressure on) policy makers and then to assure the effectiveness of the system by satisfying its ultimate goal: the implementation of valuable initiatives to promote the efficiency of energy uses.

The application of the SSM methodology structured the learning about the main actors regarding the promotion and implementation of EE initiatives, and the selection of a set of possible users of a new method for the assessment of initiatives: the Energy Agency, the Energy Market Regulator, the regulated energy companies and the supply (retail) companies.

One step resulting from the comparison stage was the study of the most relevant methodologies that have been used to handle this problem, namely the Standard Practice Manual from California (CEC\&CPUC,1987; CPUC,2001,2003), the European Benefit/Cost Methodology (SRCi, 1996) and the Low Income Public Purpose Test used in California (LIPPT, 2001). This stage was a source for the objectives identified but it also highlighted some difficulties of these approaches, namely the double counting of effects when considering multiple perspectives.

The comparison and debate stage can be in general a rich source for uncovering objectives and concerns. When comparing models with real-world activities, it may be discussed why each discrepancy detected may be considered a negative (or a positive) aspect. Finally, when defining possible changes, the discussion about whether these changes are desirable and feasible, asking "why / why not" questions may again reveal new objectives.

In the workshops, the current methodologies of assessment were compared with the conceptual model, and their components were analysed. The different DMs were confronted with the available perspectives in each methodology, showing the way they could reflect their 
true points-of-view. Most of the objectives then revealed were specific cases of objectives listed before, but a few more interesting ideas can be observed in table 4 .

\section{Structuring a tree of fundamental objectives}

\subsection{Value Focused Thinking}

SSM was useful to uncover a "cloud of objectives" for each potential evaluator of EE initiatives, but this cloud still lacked structure. Since one of the aims of this work was to structure a set of objectives to assess any EE initiative, and not the evaluation of a defined set of initiatives, the concepts presented in Keeney's Value Focused Thinking (Keeney, 1992) seemed ideal to handle the results from the SSM study and develop adequate trees of criteria. Hence, we used several "devices" described in Keeney (1992) to expand and refine the list of "objectives" obtained at the end of the SSM workshops and to define the structures "hierarchy of fundamental objectives and network of means-ends objectives" that would comply with the set of desirable properties defined by Keeney (essential, controllable, complete, measurable, operational, decomposable, non-redundant, concise, and understandable).

Alternatives already known can be used to identify values not yet reflected on the list of objectives. Several types of EE initiatives were then used to assess completeness of the list of objectives developed (italics is used to highlight new potential objectives):

Information campaigns: This kind of initiatives targeting the "information market barrier" has usually a high uncertainty about their results. There are no guarantees either of delivery or persistence. However, the target audience is potentially very large.

Audits: This kind of direct interventions may have a good participation and some guarantees of success and persistence, but they are very expensive considering the possible target. The evaluation is possible and reliable.

Technology procurement: This market transformation strategy addresses the barriers of "lack of technology", "initial high cost" and "information". Benefits regarding the employment, the economic growth and the persistence of effects can be seen as advantages for this type of strategy.

Contracts for Performance: These initiatives assure a higher reliability and are typically more successful at the expense of a higher cost or lower profit.

Direct incentive to end-user: These are the simplest and cheapest initiatives at the expense of a lower reliability.

EE initiatives are often implemented as alternatives to investments in new capacity of generation, transmission and distribution. The discussion of the advantages and disadvantages 
of these "supply-side" options over EE improvements was also undertaken with the aim of uncovering values useful to differentiate "demand-side" options. The analysis covered different kinds of generation options such as renewable, conventional and nuclear, and also network expansion. Many of the values discussed were already uncovered in previous steps of this work, but there are a few which may be considered new contributions such as the reduction of opposition from population, time to delivery, or reduction of the probability of accidents.

As a particular case, the use of extreme alternatives, the best and the worse, real or fictitious, can raise issues which otherwise would probably be forgotten. The analysis of the reasons for considering a given initiative an example of the best or worst is a practical way of identifying objectives. As an example, the extreme alternative of not meeting the demand would produce black-outs, failing with the quality of service. Another extreme case would be not to serve a customer on a difficult location due to the high connection costs (or capacity constraints), failing with an equity obligation, being the equity issue an important value to consider.

As in the previous case, the analysis of what can be considered a classification failure has good chances of revealing values to consider. It is difficult to analyse failed analysis because usually they are not published. A wrong analysis of an EE initiative may result in the waste of money, the loss of reliability due to the failure to balance demand with supply or a negative impact on employment and economic growth.

The use of targets, constraints and guidelines is another possible source of hidden objectives. Usually, targets (e.g., the Kyoto agreement) are matched or not, but they can be used to refine an objective. Constraints (e.g., the budget of each promoter, the jurisdiction of the DM) are like targets but in this case they eliminate every alternative which does not comply with them. Guidelines (e.g., the energy policy guidelines) are less restrictive than targets or constraints. They are generally helpful in the definition of relevant objectives. A good part of these devices were also used internally to the SSM study.

A final step is the structuring of objectives into hierarchies. Keeney (1992) defines two important structures, the hierarchy of fundamental objectives and the network of means-ends objectives. The first one identifies the values to use in the decision process. The second may produce alternatives to judge. Our main concern is related to the first structure but the identification of means objectives and end objectives is crucial to it. The lists of objectives were then subject to an analysis to identify which of them were end-objectives and which 
were means that lead to that end. The resulting trees of objectives are illustrated in figures 3,4 and 5 and presented in the next section.

\subsection{The Energy Efficiency Agency and the Regulator}

The trees of objective of the two "public" entities, the Agency and the regulator, share a common "societal objectives" sub-tree due to their common goal of maximising the societal benefit of EE initiatives. Their perspective is completed with an "Operational objectives" subtree which defines the objectives specific to each entity. This formulation may lead to some double counting of impacts (e.g. initiative cost to society includes part of the impact on rates, the incentives, part of the net bill reductions, the participant additional costs), but has advantages in terms of clearness.

The shaded boxes represent the levels where evaluation may occur, corresponding to the criteria to use within the multicriteria evaluation method. The choice of some aggregation levels needs additional explanations:

- The reduction of atmospheric pollution emissions due to EE initiatives is harder to quantify than environmental impacts from supply side options due to the variable mix of generation. The common way of quantifying those impacts is to apply the average emission levels to the total $\mathrm{kWh}$ of avoided generation. As these average emission levels are also controversial and there is no need to change the measurement units, the avoided $\mathrm{kWh}$ can be the proxy measure of the reduction of atmospheric pollution. The same measure can serve as a proxy for the reduction of the dependence of foreign resources and even the reduction in generation costs.

- A similar explanation applies to the reduction of animal and human impacts of capacity expansion. It is quite difficult to assess the consequences of building new generation plants or power lines in terms of animal life and even human life in a complete and reliable manner and it is almost impossible to predict how an EE initiative will reduce these costs. It is nevertheless usually accepted that these cost reductions will be a function of the avoided capacity. Avoided capacity (in MW or other unit of power) can then be a reliable proxy for these benefits as well as of the energy system reliability improvements and capacity costs.

The remaining criteria needing explanation are:

Improvements in welfare: Ancillary benefits of EE initiatives may include improvements in comfort, eventually resulting in health benefits and even reduction of deaths (Davis et al., 2000; Clinch and Healy, 2001), in addition to the health benefits resulting from less 
pollution (already accounted for in the consumption impacts objective). For instance, the "take-back" effect of increasing the use of energy services as a result of the bill reduction represents an increase in welfare that should be considered explicitly. The complex nature of this criterion suggests it should be used on a qualitative basis.

Employment/Economy benefits: The impact of EE initiatives in terms of employment creation and domestic product may be positive (e.g., creation of new Energy Service Companies) or negative (e.g., reduction of sales of a local end-use manufacturer which cannot follow the new standard). The difficult computation of quantitative data may suggest the use of a qualitative scale but in certain cases these impacts have been computed through simulation (Nicolls et al., 1994). Several ex-post evaluation studies are also available as a reference (ACE, 2000; Geller et al., 1992; Wade et al., 2000).

Benefits in other resources: Some initiatives may affect on a positive or negative way other resources. For instance, initiatives promoting low flux shower-heads, with the aim of reducing energy consumption, also contribute to reduce the potable water depletion. The variable nature and probable difficulty of assessment suggests a qualitative assessment.

Total implementation costs to society: These are simply the implementation and monitoring costs, since bill reductions to participants are cancelled with sales reduction to companies and the avoided costs are already considered through energy and capacity savings. This criterion can be measured in monetary terms.

Budget share: The Agency has a limited budget to promote EE, hence the share allocated to each initiative can be a matter of concern (e.g., the Agency might not want a single initiative to take $70 \%$ of its budget). This can be measured in monetary units, or in relative terms as a percentage.

Evaluation capability: The ability to do an ex-post evaluation of the initiatives is important to be able to verify the efficacy of the initiative and to demonstrate the adequacy of the investment. Some initiatives are impossible to evaluate reliably (information initiatives) and others are easily auditable. This is a qualitative criterion.

Market transformation: Some initiatives have persistent results, transforming the market on a definitive basis but others only affect a limited number of consumers and perhaps only as long as initiatives last. The performances in this criterion are evaluated qualitatively.

Strategic objectives: Having to comply with external (energy policy) or internal guidelines, the agency and the regulator need to assess each initiative according with such strategic objectives. Companies have a similar objective to express the adequacy of the initiative to the company's strategic plans, e.g. if the new business area created by an initiative meets 
an objective of diversification or, contrarily, goes against the objective of focusing on the core business. Again, this is a criterion which can only be assessed on a qualitative basis.

Impact on rates: One of the main concerns of the regulator, the impact on rates is defined as the initiative costs, including loss of sales, which are allowed by the regulator to be recovered through a general rate increase. It can be measured in absolute terms or with respect to the total number of customers or to the total electricity sales on a reference year. A negative value would mean that the initiative reduces rates.

Bill reductions: The reduction of the energy cost to participant consumers is part of the regulator's objective of caring about consumers and counterbalances the general rate impact and utility's costs not covered.

Utility's costs not covered: A part of the initiative costs, including loss of sales, may not be covered by the allowance to increase rates, and in this case the regulator must consider this issue in the analysis.

\subsection{Energy companies}

Both regulated and competitive supply companies share the same structure of objectives (figure 5) although some objectives may have low significance to one or the other kind of company. A few explanations are presented next.

Profits: Initiatives may affect both operational and structural costs in a positive or negative way. Besides the fact that both can be directly measured in monetary units, they may have different importance to the DM due to the permanent nature of the structural costs. Structural net benefits are the initiative's net benefits considering the structural cost reductions such as avoided costs of capacity and eventual changes in staff cost, equipment, and training costs.

Market share: On a competitive market, the customer base is no longer stable and EE initiatives may play a role in the increase or decrease of market share. This criterion may have to be measured in qualitative terms.

Public Image: The building of a positive public image may have consequences in the negotiation power of the companies, with the regulator, the government, the stock exchange or the customers. EE may help creating the image of a "green company".

Compatibility with status-quo: The implementation of initiatives can be hindered due to resistances in the company's staff, e.g. by a change in paradigm from sales to "no-sales" or difficulties in getting it approved by higher management levels. Different initiatives may 
have different compatibilities with the "status-quo", to be captured by this qualitative measure.

Societal obligations: Both the regulatory contract of regulated companies and the concession contract to competitive supply companies may have societal obligations, e.g. the obligation to increase the efficiency of end-uses by $x \%$ regarding the reference year's levels, or to promote the equity regarding the access to energy. Different initiatives may address these obligations in different ways, thus needing a qualitative assessment.

\section{Discussion and concluding remarks}

The need for a generic evaluation model to use as an alternative to Cost-Benefit analysis when deciding about financing or implementing any $\mathrm{EE}$ initiative or portfolio of initiatives motivated a value-thinking approach, after establishing a first set of assumptions like the role of each actor and their most important concerns regarding these initiatives. This resulted from a problem structuring phase in which the use of the Soft Systems Methodology was very helpful. It performed very well as a way of structuring an internal debate about the context in which EE can be promoted, addressing the new realities of the electricity market, and the reasons that each of the agents in that market have to promote or contest initiatives with that aim.

In this intervention, SSM played a central role in suggesting questions for eliciting a "cloud of objectives" that each potential evaluator of EE initiatives may pursue. The guidelines provided by Keeney (1992) in the framework of "Value Focused Thinking" were then used to amend and structure these objectives, resulting in trees of fundamental objectives which can be converted into criteria for a multicriteria evaluation approach. The tools of SSM and VFT were hence used in sequence. Nevertheless, the value-focussing was already present during SSM and the learning that stemmed from SSM was still present when using Keeney's devices, hence the combined use of these methodologies is richer than a simple sequence.

Although there is no guarantee that the same problem analysed by other team or even by the same team in a different occasion would lead to the same results, the exhaustive learning catalyzed by the SSM study, and then with the VFT approach, combined with the ex-post interviews with some experts, explicitly provided confidence about the completeness of the model. We found that SSM is a viable alternative to using mapping-based problem structuring methods to help unveiling a set of objectives for structuring a multi-criteria decision analysis model. 
In parallel with the description of the case study, we suggest a list of elicitation questions to ask during an SSM intervention, aiming at revealing the objectives of a DM in multicriteria analysis interventions in general (summarized in Table 5). The answers to these questions may unveil the objectives of the DM concerning the evaluation of options in the creation or modification of a system. It will be normal that many of these questions lead to the same objectives, since the values that drive the stakeholders behaviour in their activities will also drive their behaviour during all the stages of SSM. It can also be expected that the effort to unveil and make these objectives explicit will affect the course of the SSM intervention.

Future research is of course needed to help establishing SSM as an alternative to using mapping based methods, and especially as an alternative to using no formal method at all. This requires an array of different studies in different contexts in terms of group dynamics, cultures, or backgrounds.

The methodology of using SSM for structuring an MCDA model also deserves further research and experimentation, exploring variants that cannot be explored when conducting one intervention. Namely, we deem that it may be useful to consider, simultaneously or sequentially, two systems: $\mathrm{S}$ - the existing system or potentially existing system affected by the actions (the alternatives), and $\mathrm{E}$ - a system to evaluate actions affecting S. For instance, if the problem of concern for a given University is the selection of candidates to enter an MBA, then S could represent the University and E could represent the selection process (committees, rules, tests, etc.). An important characteristic of the SSM is precisely its ability to model multiple relevant systems, each one potentially bringing fresh perspectives on the elicitation of objectives.

We end this paper with an epilogue. The first author of this paper did complete his $\mathrm{PhD}$ addressing the evaluation of EE initiatives, building an MCDA sorting model that was confronted with a public database of past evaluation results in developed countries (Neves et al., in print). INESC Coimbra did learn a lot from this intervention, and was at a privileged position to participate in the public discussion of the evaluation model proposed by the Portuguese Entity for the Regulation of the Energy Sector when it launched a program to promote EE. Later, INESC Coimbra was chosen by the main Portuguese electrical utility as one of the consultants for proposing EE initiatives to be financed on a competitive basis in the framework of a nationwide plan for the promotion of efficiency in the use of electricity, involving both intangible and tangible initiatives. Indeed, the trees of objectives could be used to help generating alternatives, one of the most useful purposes of Keeney's Value Focused Thinking, and also to asses what was interesting for the company to propose. 


\section{Acknowledgements}

We are indebted to the specialists that attended the workshops for their active participation in the discussions: Eng. Vítor Baptista (REN), Eng. José Carvalho Neto (DGE), Eng. Paulo Santos (CONTAWATT, lda), Dr Artur Trindade (ERSE), Dr Faustino Cordeiro (FENACOOP). Fruitful comments provided by Ralph Keeney on an earlier draft of this work are also gratefully acknowledged. This research has been partly funded by Portuguese Foundation for Science and Technology under Project Grants POCI/EGE/58371/2004, POCI/ENR/57082/2004, and PTDC/ENR/64971/2006.

\section{References}

ACE - Association for the Conservation of Energy. Energy efficiency and jobs: UK issues and case studies. Report, Energy Saving Trust. 2000

Bana e Costa CA, Ensslin, L, Corrêa, ÉC, Vansnick, JC. Decision support systems in action: integrated application in a multicriteria decision aid process. European Journal of Operational Research 1999;113; 315-335.

Belton V, Ackerman, F, Shepherd, I. Integrated support from problem structuring through to alternative evaluation using COPE and V.I.S.A. Journal of Multi-Criteria Decision Analysis 1997; 6; 115-130.

CEC\&CPUC. Standard Practice Manual: Economic Analysis of Demand-Side Management Programs. California Public Utilities Commission and California Energy Commission; 1987.

CPUC. Energy Efficiency Policy Manual. California Public Utilities Commission, version 1; 2001.

CPUC. Energy Efficiency Policy Manual. California Public Utilities Commission, version 2; 2003.

Checkland, P. 1986. The Politics of Practice. IIASA Roundtable, "The Art and Science of Systems Practice”, Laxenburg, Austria. November 1986.

Checkland P. 1989a. An application of soft systems methodology. In: Rosenhead (Ed); 1989; p. $71-100$.

Checkland P. 1989b. Soft systems methodology. In: Rosenhead (Ed); 1989; p. 43-70.

Checkland P. Systems Thinking, Systems Practice. John Wiley \& Sons: Chichester. 1990

Checkland P, Scholes, J. Soft Systems Methodology in Action. John Wiley \& Sons: Chichester; 2000. 
Clinch JP, Healy JD. Cost-benefit analysis of domestic energy efficiency. Energy Policy 2001; $29 ; 113-124$.

Daellenbach HG 1997. Multiple criteria decision making within Checkland's Soft Systems Methodology. In: J. Clímaco (ed), Multicriteria Analysis, Springer-Verlag: BerlinHeidelberg; 1997; p-51-60.

Davis DL, Krupnick A, McGlynn G 2000. Ancillary benefits and costs of greenhouse gas mitigation. In: Ancillary Benefits and Costs of Greenhouse Gas Mitigation. Intergovernmental Panel on Climate Change (IPCC), OECD; 2000.

European Commission. ExternE: Externalities of Energy - Methodology. Directorate-General XII; 1999.

European Commission. ExternE: Externalities of Energy - National Implementation. Directorate-General XII; 1999.

Geller H., DeCicco J., Laitner S. Energy efficiency and job creation. Report ED922, American Council for an Energy Efficienct Economy. 1992.

Hobbs BF, Meier P. Energy Decisions and the Environment: A Guide to the Use of Multicriteria Methods. Kluwer Academic Publishers. 2000.

Keeney RL. Value-Focused Thinking. Harvard University Press, Cambridge. 1992.

Keeney RL, McDaniels TL. Identifying and structuring values to guide Integrated Resource Planning at BC Gas. Operations Research 1999; 47; 651-662.

Krewitt W. External costs of energy - do the answers match the questions? looking back at 10 years of ExternE. Energy Policy 2002; 30; 839-848.

LIPPT. Low-Income Public Purpose Test. Final report, RRM Working Group's Cost Effectiveness Committee. 2001.

Montibeller G, Belton V, Ackermann F, Ensslin L. Reasoning Maps for Decision Aid: An Integrated Approach for Problem-Structuring and Multi-Criteria Evaluation. Journal of the Operational Research Society 2008; 59; 575-589.

Neves L. Avaliação multicritério de iniciativas de eficiência energética (Multicriteria evaluation of energy efficiency initiatives), $\mathrm{PhD}$ dissertation in Electrical Engineering, Faculty of Science and Technology, University of Coimbra. 2005.

Neves LMP, Martins AG, Antunes CH, Dias LC. Using SSM to rethink the analysis of energy efficiency initiatives. Journal of the Operational Research Society 2004; 55; 968-975.

Neves LP, Martins AG, Antunes CH, Dias LC. A multi-criteria decision approach to sorting actions for promoting energy efficiency, Energy Policy, to appear. 
Nicolls AK, LaMontagne J, Jones RE, Shankle SA, 1994. Estimating the impacts of federal efforts to improve energy efficiency: The case of buildings. Tech. rep., the U.S. Department of Energy, presented at The World Oil \& Gas Industrial 16th North American Conference: In the 21st Century, Dallas, Texas, November 1994.

Petkov D, Petkova O, Andrew T, Nepal T. Mixing Multiple Criteria Decision Making with soft systems thinking techniques for decision support in complex situations. Decision Support Systems 2007; 43; 4; 1615-1629.

Rosenhead J. (Ed.), 1989. Rational Analysis for a Problematic World: Problem Structuring Methods for Complexity, Uncertainty and Conflict. John Wiley \& Sons, Chichester.

Rosenhead J, Mingers J (eds), 2001. Rational Analysis for a Problematic World Revisited: Problem Structuring Methods for Complexity, Uncertainty and Conflict. John Wiley \& Sons, Chichester.

SRCi, Feb. 1996. European B/C Analysis Methodology (EUBC) - A Guidebook For B/C Evaluation of DSM and Energy Efficiency Services Programs. A Project Advisory Commitee and SRC International ApS, prepared for the European Commission (DG XIIV).

Wade J, Wiltshire V, Scrase I. 2000. National and local employment impacts of energy efficiency investment programmes. Final report to the European Commission, Association for the Conservation of Energy. 


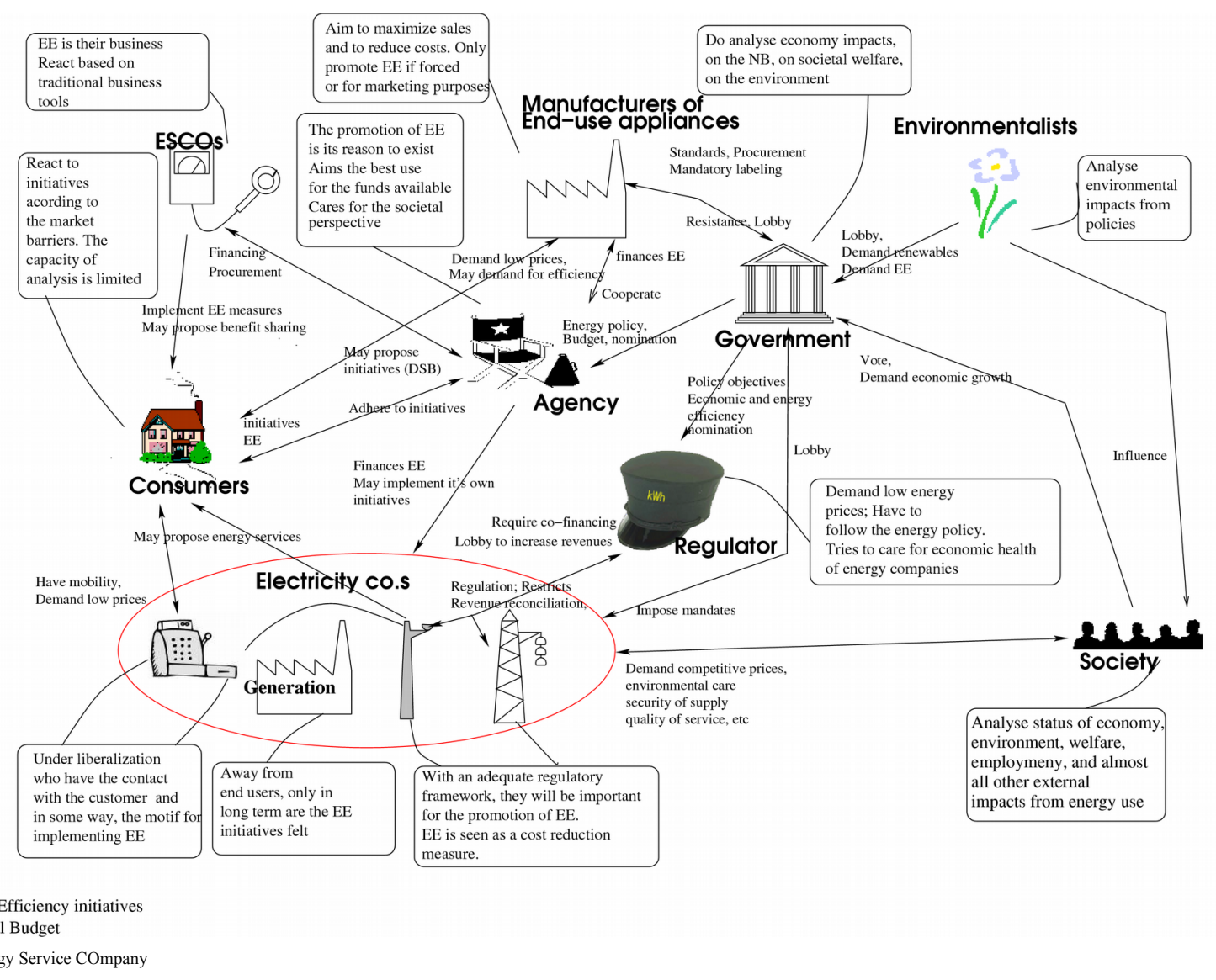

Figure 1: Rich-picture of the problem situation 


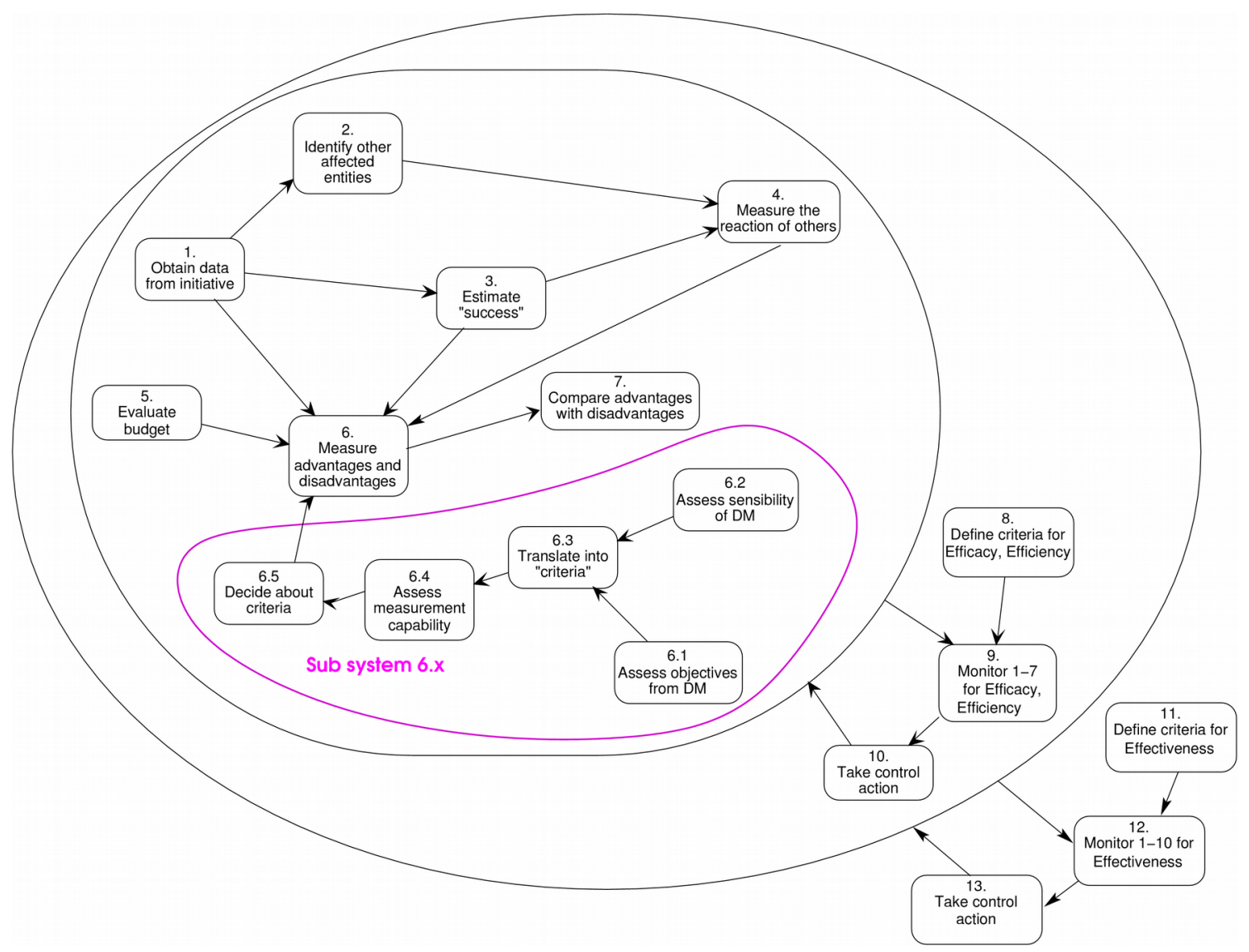

Figure 2: Conceptual model of the Analysis system 


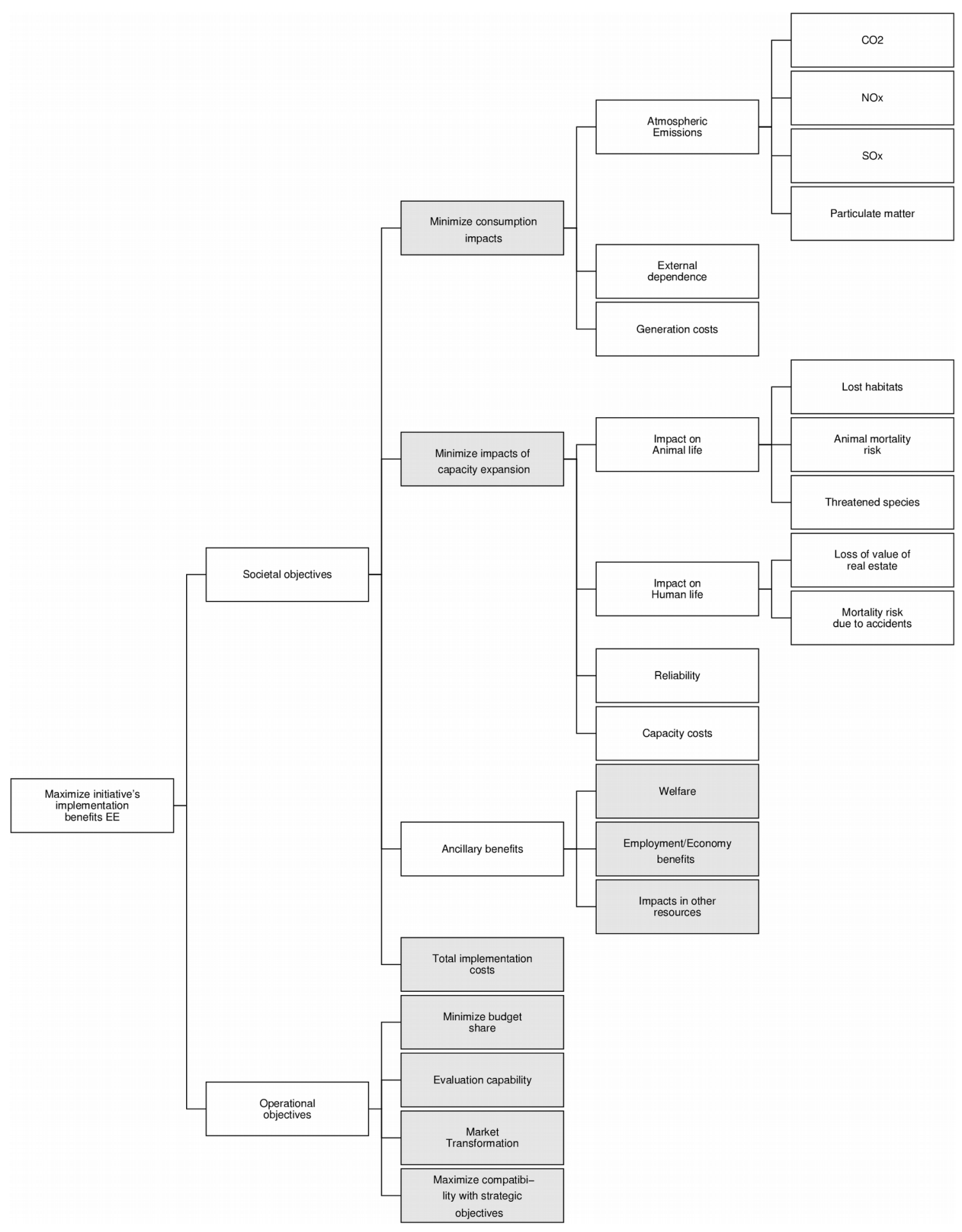

Figure 3: Hierarchy of fundamental objectives of the Agency 


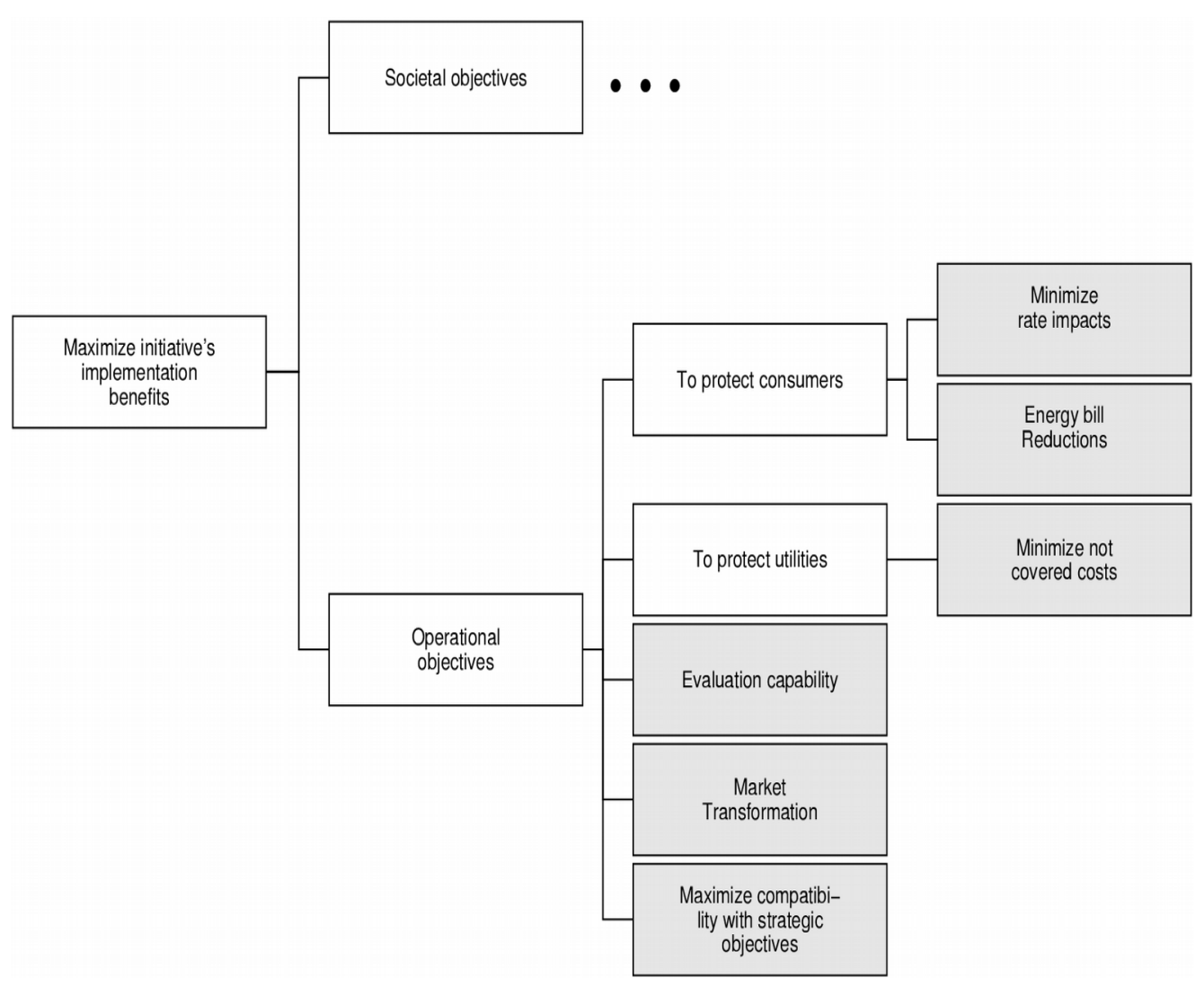

Figure 4: Regulator's objectives (without societal objectives) 


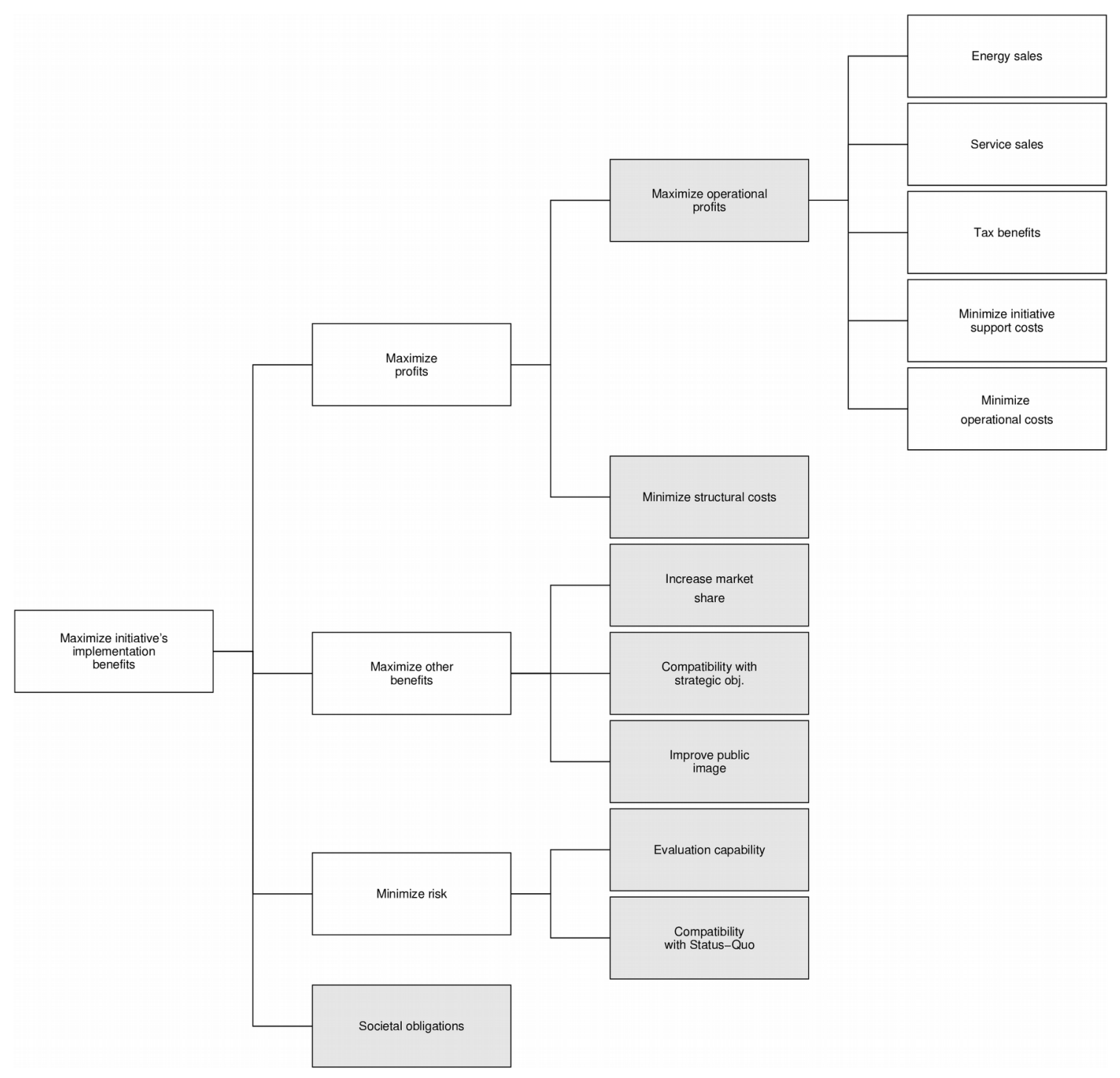

Figure 5: Fundamental objectives of Energy companies 


\begin{tabular}{|c|c|}
\hline Agency & Regulator \\
\hline $\begin{array}{l}\text { Societal welfare } \\
\text { Budget constraints } \\
\text { Policy constraints } \\
\text { Third party support }\end{array}$ & $\begin{array}{l}\text { Societal welfare } \\
\text { Companies welfare } \\
\text { Policy constraints } \\
\text { Minimise energy tariffs }\end{array}$ \\
\hline \multicolumn{2}{|c|}{ Societal objectives common to agency and regulator } \\
\hline \multicolumn{2}{|c|}{$\begin{array}{cl}\text { Reduction of environmental impacts: } \\
\text { - } & \text { Emission of atmospheric pollution } \\
\text { - } & \text { Water pollution } \\
\text { - } & \text { Habitangering of species } \\
\text { - } & \text { Visual impaction } \\
\text { - } & \text { Land requirements } \\
\text { - } & \text { Health effects }\end{array}$} \\
\hline
\end{tabular}

Table 1: Objectives and concerns unveiled during the "finding-out" stage: Agency and Regulator

\begin{tabular}{|l|}
\hline \multicolumn{1}{|c|}{ Companies } \\
\hline \hline Cost minimisation \\
To attract and/or keep customers \\
Regulatory or contractual constraints \\
Maximise revenues (minimise revenue loss) \\
\hline
\end{tabular}

Table 2: Objectives and concerns unveiled during the "finding-out" stage: Companies

\begin{tabular}{|l|l|l|}
\hline \multicolumn{1}{|c|}{ Agency } & \multicolumn{1}{|c|}{ Regulator } & \multicolumn{1}{c|}{ Companies } \\
\hline \hline $\begin{array}{l}\text { To obtain third-party financing } \\
\text { To justify budget }\end{array}$ & $\begin{array}{l}\text { Minimise interference with } \\
\text { other entities } \\
\text { To justify rates }\end{array}$ & $\begin{array}{l}\text { Maximise acceptability by the regulator or } \\
\text { other sponsor } \\
\text { Cost recovery } \\
\text { Minimum pay-back }\end{array}$ \\
\hline
\end{tabular}

Table 3: Objectives revealed in root definition and CATWOE

\begin{tabular}{|c|c|}
\hline Agency \& Regulator & Companies \\
\hline \hline Cooperation by Manufacturers and ESCOs & New business opportunities \\
Minimize costs of energy supply to society & Independence from consumption \\
Minimize costs of participation & Minimize possible problems with human resources \\
Minimize use of other resources (e.g., water) & and equipment \\
Maximize productivity & Control load \\
Minimize employment reductions & Minimize investments \\
Compliance with targets (e.g., international & Minimize losses \\
agreements) & Maximize reliability \\
\hline
\end{tabular}

Table 4: Objectives revealed in the comparison and debate stage 


\section{Elicitation questions}

The finding out stage:

Why is the situation a problem?

What are the objectives of each actor?

What norms of behaviour exist for each actor?

What constitutes good performance in each actor's role?

Through what 'commodities' is power manifested, and how are these commodities obtained, preserved and passed on?

The system definition stage

Customer: what benefits or harm may result?

Actors: what would define a good role?

What is the Weltanschauung?

Owner: why would it stop, downgrade, or upgrade the activity?

What are the environmental constraints?

By which criteria would effectiveness, efficacy and efficiency be measured?

Why is this activity $A$ important?

The system comparison stage

Is this difference between the models and the realword activities a negative or positive aspect, and why? (for each debated difference)

Why is / isn't this change desirable? (for each debated change)

\section{Contribution of the answer}

Objectives that are not currently being met satisfactorily.

Objectives for each actor.

Norms and social constraints can exist to meet the objectives of some stakeholder(s).

Objectives for the actor.

Objectives of a political nature regarding the distribution and the control of power.

Objectives to maximize or minimize, resp.

Objectives for the actor.

May entail objectives or constraints (that can also be reframed as objectives).

Owner's objectives.

Constraints can be reframed as objectives.

Objectives concerning these aspects.

Objectives pursued by the activity.

Objectives whose degree of achievement would change.

Objectives whose degree of achievement would change.

Table 5: Guidelines for using SSM to reveal MCDA objectives. 